\title{
COLLECTING DUCT CARCINOMA ASSOCIATED WITH ONCOCYTOMA
}

\author{
GEORGE M. YOUSEF, GERSHON C. EJECKAM, LEONICO M. BEST, ELEFTHERIOS P. \\ DIAMANDIS
}

\author{
Discipline of Pathology, Memorial University, St. John's, Health Care Corporation of St. John's, \\ Newfoundland, and Department of Pathology and Laboratory Medicine, Mount Sinai Hospital, Toronto, \\ Ontario, Canada
}

\begin{abstract}
Collecting duct carcinoma (CDC) is a rare, highly aggressive malignant neoplasm that arises from the collecting duct epithelium of the kidney. CDC was reported to coexist with renal cell and transitional cell carcinomas. We report a rare case of CDC associated with oncocytoma, confirmed by the characteristic histological appearance and immunohistochemistry. We also review the epidemiological, histological and immunohistochemical criteria for diagnosis, in addition to the genetic and cytogenetic aberrations reported in the literature. Identification and reporting CDC is important for the establishment of treatment strategies and monitoring prognosis.
\end{abstract}

Key words: kidney neoplasms; collecting ducts, kidney; oncocytoma

Int Braz J Urol. 2005; 31: 465-9

\section{CASE REPORT}

A 66-year old male with a history of non-insulin dependent diabetes, hypertension and chronic prostatitis presented gross hematuria, abdominal pain and renal failure. At the time of diagnosis, a CT scan showed a $4 \mathrm{~cm}$ poorly enhancing mass at the anterior aspect of the lower pole of the kidney, with associated lymph node and spinal cord metastasis. The patient underwent radical nephrectomy and was placed on hemodialysis until he died shortly following the procedure.

\section{Pathologic Findings}

The main tumor mass was $6.0 \times 5.0 \times 5.0 \mathrm{~cm}$ in the lower pole of the kidney. The cut surface was firm and grayish white with focal areas of hemorrhage and necrosis. In addition, there were multiple coalescing small grayish nodules scattered throughout the kidney.
Microscopically, the tumor consisted of a high-grade tubulopapillary and solid lesion. Micropapillary to frank papillary patterns with central fibrovascular stalks were present. Nuclei were large, vesicular and possessed large prominent nucleoli. In some areas, the tumor showed a tubuloglandular pattern on a background of a desmoplastic stroma infiltrated by inflammatory cells. Extensive tumor necrosis with calcification was present. Tumor cells infiltrated the renal capsule, perirenal fat, and the adrenal gland. Extensive lymphatic and vascular invasion were present. On immunohistochemistry, tumor cells were positive to Ulex European agglutinin 1 lectin, vimentin, and distal tubular marker EMA (Figure-1). Another nodule of a renal oncocytoma, measuring $1.0 \mathrm{~cm}$ in diameter with extensive hemorrhage was also found in the renal cortex (Figure-2). This was positive for AE1/AE3, negative for CK7 and Hale's colloidal iron and shows mitochondria on electron microscopy. 


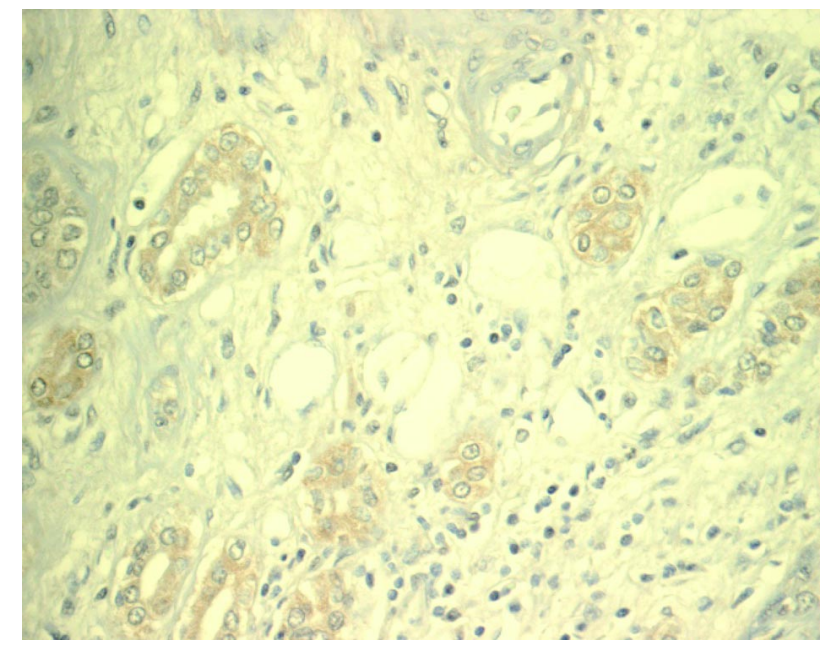

Figure 1 - Immunohistochemistry shows positivity to Ulex European agglutinin 1 lectin, which strongly supports the diagnosis of $C D C$.

\section{COMMENTS}

Collecting duct carcinoma (CDC) is a rare, highly aggressive renal cell carcinoma. On presentation, CDC is metastasized to regional lymph nodes in about $80 \%$ of cases. There is a white male preponderance (1).

Grossly, the tumor may commence at the cortico-medullary junction but due to its aggressiveness, can spread to the entire kidney and beyond on diagnosis. Unlike conventional renal cell carcinoma, CDC is not usually circumscribed, shows no bright yellow coloration and only small to punctate hemmorrhagic areas. Microscopically, CDC is a highgrade malignancy with large vesicular nuclei and large prominent nucleoli. There is no accumulation of macrophages in the stroma. These features assist in differentiating CDC from papillary renal cell carcinoma. On immunohistochemical studies, tumor cell positivity with antibodies to Ulex European agglutinin 1 lectin strongly suggests the diagnosis of CDC. The tumor is also positive to peanut agglutinin (PNA), vimentin, lysozyme, distal tubular marker EMA, and high molecular weight cytokeratin, and negative for proximal tubular markers (Leu-M1) (2). This is in contrast to conventional (clear cell) renal cell carcinoma, which expresses pancytokeratin but is negative for high molecular weight cytokeratin. CDC pro-

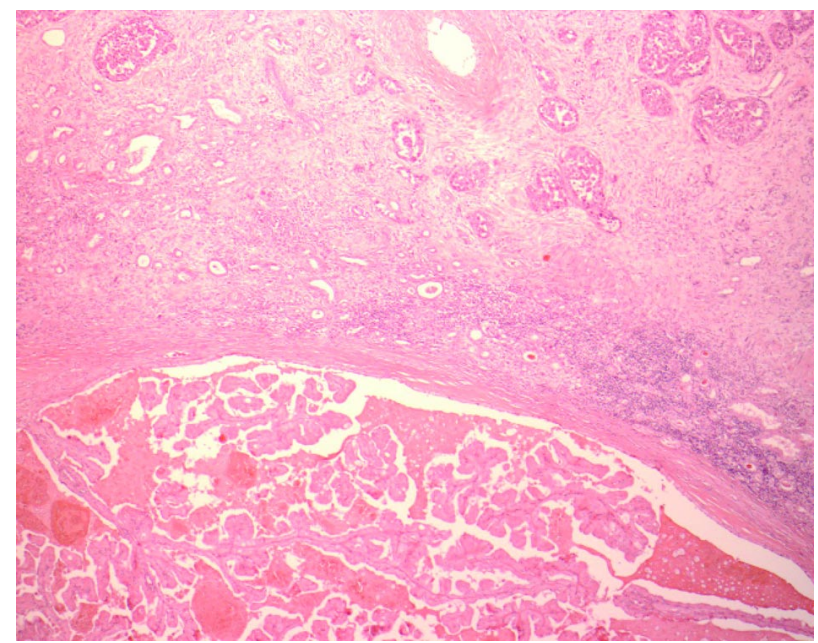

Figure 2-HE staining showing the co-existence of CDC (top), with a nodule of oncocytoma (bottom).

duces intracellular mucin, which can be demonstrated by mucicarmine and PAS stains.

Chromosomal features of CDC are distinct. Comparative genomic hybridization revealed a gain of chromosomal material on chromosome 3 and a loss of chromosomal material on chromosomes 12 and 22 (3). There is also a loss of heterozygosity of $8 p$ and 13q. A loss of chromosome arms 6p, 8p, 13q and 21q was reported in $40-50 \%$ of cases.

The coexistence of multiple primary cancers in the kidney has been reported. CDC is reported to co-exist with other renal tumors as RCC and transitional cell carcinoma. To our knowledge, this is the first report that shows this rare coincidence of CDC with oncocytoma. The association of CDC with oncocytoma is not surprising, since a similar origin from the distal nephron was postulated for both.

Oncocytoma should be differentiated from the closely related chromophobe renal cell carcinoma (CRCC). In CRCC, the nuclei are wrinkled with hyperchromatic nuclei while those of oncocytoma are perfectly round. Binucleation and multinucleation is more common in CRCC. Well-defined cell membranes and perinuclear halos are seen in CRCC. The cytoplasm Hale's colloid iron staining is only positive in CRCC. In electron microscopy, CRCC shows cytoplasmic vesicles while oncocytoma shows mitochondria. 
In conclusion, we report on a case of CDC which shows a rare association with renal oncocytoma. Accumulation of data on CDC will allow for the establishment of better treatment strategies and monitoring prognosis.

\section{REFERENCES}

1. Storkel S, Eble JN, Adlakha K, Amin M, Blute ML, Bostwick DG, et al.: Classification of renal cell carci- noma: Workgroup No. 1. Union Internationale Contre le Cancer (UICC) and the American Joint Committee on Cancer (AJCC). Cancer 1997; 80: 987-9.

2. Singh I, Nabi G: Bellini duct carcinoma: review of diagnosis and management. Int Urol Nephrol. 2002; 34: 91-5.

3. Meloni-Ehrig AM: Renal cancer: cytogenetic and molecular genetic aspects. Am J Med Genet. 2002; 115: 164-72.

Received: February 24, 2005

Accepted after revision: June 29, 2005

\author{
Correspondence address: \\ Dr. George M. Yousef \\ Health Sciences Center \\ 300 Prince Philip Drive \\ St. John's, NL, A1B 3V6 \\ Ontario, Canada \\ Fax: + 17097778625 \\ E-mail: gyousef@mtsinai.on.ca
}

\title{
EDITORIAL COMMENT
}

\section{Adult Renal Epithelial Neoplasms}

The case report presented on page 465, "Collecting Duct Carcinoma Associated with Oncocytoma," gives us an opportunity to comment on the importance of classifying the renal epithelial neoplasms in adults. The most recent WHO publication brings the classification shown in Table1 (1). Such neoplasms have completely distinct macroscopic, microscopic, genetic features and clinical behavior, and a proper histological classification is fundamentally important when determining the prognosis and management of these tumors.

Oncocytoma is a benign epithelial neoplasm. There are no consistent reports of recurrence or metastases, and surgical treatment is curative.
Table-1

\section{Classification of Renal Epithelial Neoplasms - WHO 2004}

Clear cell carcinoma

Multilocular clear cell carcinoma

Papillary renal cell carcinoma

Chromophobe renal cell carcinoma

Collecting duct or Bellini's carcinoma

Renal medullary carcinoma

Carcinomas with Xp11translocation

Carcinoma associated with neuroblastoma

Spindle cell and mucinous tubular carcinoma

Unclassified renal cell carcinomas

Papillary adenoma

Oncocytoma 
Among the malignant tumors, the collecting duct (or Bellini's) carcinomas are the most aggressive. They are fortunately rare $(<1 \%)$, affect young individuals and only half of the cases present metastatic disease. Interestingly, they respond poorly to immunotherapy, the classical treatment for renal cell carcinomas, and appear to be responsive to chemotherapy (2).

Clear cell carcinoma, the most common type (70\%), is the second most aggressive with a mean survival of $69 \%$ in 5 years (3). Its cystic or multilocular variant shows a very good behavior, with $100 \%$ of survival in 5 years (4). $75 \%$ of the time, its carcinogenesis route is related to loss of the VHL gene, which controls the hypoxia-induced factor (HIF-1) related to angiogenesis, $\mathrm{pH}$ control, glucose transport, cell proliferation and migration (5). The importance of this knowledge is the development of new treatment lines using inhibitors of tyrosine kinase and of the RAS/ RAF signaling pathway, which are the focus in several clinical trials, with encouraging results (6).

The sarcomatoid carcinoma is not a histological subtype, but a dedifferentiation of any CCR types. It represents a poor prognosis factor by itself (7).

The spindle cell and mucinous tubular carcinomas are typically low-grade tumors and show good clinical behavior (8). Other tumors, whether equally rare or recently described, have a still unknown behavior, and both urologists and pathologists must be alert in order to recognize these new entities.

\section{REFERENCES}

1. Eble JN, Sauter G, Epstein JI, Sesterhenn IA: World Health Organization Classification of Tumors. Pathology and Genetics of Tumours of the Urinary System and Male Genital Organs, Lyon, IARC Press, 2004.

2. Chao D, Zisman A, Pantuck AJ, Gitlitz BJ, Freedland SJ, Said JW, et al.: Collecting duct renal cell carcinoma: clinical study of rare tumor. J Urol. 2002; 167: 71-4.

3. Cheville JC, Lohse CM, Zincke H, Weaver AL, Blutte ML: Comparisons of outcome and prognostic features among histologic subtypes of renal cell carcinoma. Am J Surg Pathol. 2003; 27: 612-24.

4. Corica FA, Iczkowski KA, Cheng L, Zincke H, Blutte ML, Wendel A, et al.: Cystic renal cell carcinoma is cured by resection: a study of 24 cases with long-term followup. J Urol. 1999; 161: 408-11.

5. Linehan WM, Walther MM, Zbar B: The genetics basis of cancer of the kidney. J Urol. 2003; 170: 216372.

6. Mancuso A, Sternberg CN: What's new in the treatment of metastatic kidney cancer? BJU Int. 2005; 95: 1171-80.

7. Dall'Oglio MF, Lieberknecht M, Gouveia V, Sant'Anna AC, Leite KR, Srougi M: Sarcomatoid differentiation in renal cell carcinoma: prognostic implications. Int Braz J Urol. 2005; 31: 10-16.

8. Parwani AV, Husain AN, Epstein JI, Beckwith JB, Argani P: Low-grade myxoid renal epithelial neoplasms with distal nephron differentiation. Hum Pathol. 2001; 32: 506-12.

Dr. Katia R Leite

Laboratory of Clinical and Molecular Pathology University of Sao Paulo, USP

Sao Paulo, SP, Brazil

E-mail: katiaramos@uol.com.br

\section{EDITORIAL COMMENT}

Renal cell carcinoma is a tumor comprising several histologic subtypes, the molecular hallmarks of which support their classification as distinct entities. The most common form is clear cell or conven- tional renal carcinoma, which has been associated with mutations in the von Hippel-Lindau gene and loss of hetrozygosity at chromosome $3 p$. Next in frequency is papillary renal cell carcinoma associated 
with trisomies of chromosomes 7 and 17 and loss of chromosome Y. Chromophobe renal cell carcinoma is associated with numerous specific chromosomal losses. Chromosomal and genetic studies of collecting duct carcinomas are limited. The most characteristic changes of these aggressive tumors are deletions involving chromosomes $1,6,8,14,15,21$, and 22 . Renal oncocytoma, a benign neoplasm, most often does not present any chromosomal abnormalities.

Multicentricity is a relatively common finding in papillary renal cell carcinomas. Renal clear cell carcinoma occurs in 38 to 55 percent of patients with von Hippel-Lindau syndrome. Lesions tend to be bilateral and multicentric, are often associated with cysts, and occur at an earlier age than sporadic renal clear cell carcinoma.

Association of histologic subtypes is a rare event in kidney tumors. The reported case on page 465, "Collecting Duct Carcinoma Associated with Oncocytoma," seems to be the first report of an association of collecting duct carcinoma (a very aggressive tumor) and oncocytoma (a benign tumor). Recently, an intriguing association of renal tumors was reported.
The Birt-Hogg-Dubé (BHD) syndrome has been reported in association with renal tumors of a variety of histologic types (1). BHD was originally described in 1977 as genodermatosis characterized by autosomal dominantly inherited pale yellow-white domeshaped papules on the face, neck, and upper trunk (2). In addition to cutaneous lesions, BHD confers an increased incidence of renal tumors, lung cysts, and spontaneous pneumothorax, and have linked the BHD gene to chromosome presence of an unusual hybrid form of renal tumors with elements of oncocytoma, chromophobe renal cell carcinoma, and occasional areas reminiscent of renal clear cell carcinoma.

\section{REFERENCES}

1. Pavlovich CP, Walther MM, Eyler RA, Hewitt SM, Zbar B, Linehan WM, Merino MJ: Renal tumors in the Birt-Hogg-Dube syndrome. Am J Surg Pathol. 2002; 26: 1542-52.

2. Birt AR, Hogg GR, Dube WJ: Hereditary multiple fibrofolliculomas with trichodiscomas and acrochordons. Arch Dermatol. 1977; 113: 1674-7.

Dr. Athanase Billis

Full-Professor of Pathology State University of Campinas, Unicamp Campinas, São Paulo, Brazil E-mail: athanase@fcm.unicamp.br 